\title{
"Comparative Study Between Preoperative Clinical \& Ultrasonogram and Per Operative Laparoscopic Findings in Gall Stone Disease"
}

Md. Anwarul Haque ${ }^{1^{*}}$, Mohammed Abu Kawsar Sarker ${ }^{2}$, Md. Abu Sayem ${ }^{3}$, Lakshman Chandra Barai ${ }^{4}$, Shabyasachi Nath $^{5}$

\author{
${ }^{1}$ Junior Consultant (Surgery), Upazila Health Complex, Paba, Rajshahi, Bangladesh \\ ${ }^{2}$ Assistant Professor, Dept. of Surgery, East West Medical College \& Hospital, Dhaka, Bangladesh \\ ${ }^{3}$ Assistant Professor (Surgery), Shaheed Tajuddin Medical College, Gazipur Bangladesh \\ ${ }^{4}$ Assistant Professor (Cardiology), National Institute of Cardiovascular Diseases and Hospital, Dhaka, Bangladesh \\ ${ }^{5}$ Deputy Program Manager, Hospital Services Management, DGHS, Dhaka, Bangladesh
}

DOI: $10.36347 /$ sasjs.2020.v06i02.006

| Received: 01.02.2020 | Accepted: 09.02.2020 | Published: 12.02.2020

*Corresponding author: Md. Anwarul Haque

Abstract

Original Research Article

Introduction: Gallbladder disease is a worldwide common surgical problem. Before the advent of the laparoscopic cholecystectomy, open cholecystectomy was the standard modality of treatment for cholelithiasis and symptomatic gallbladder diseases. Objective: To see the accuracy of clinical diagnosis after ultrasonographic evaluation of gallstone and symptomatic gallbladder disease. Materials and Methods: It is a prospective study the Patients admitted in surgery wards from emergency \& outpatient department with the diagnosis of gallstone and symptomatic gallbladder disease. Total 100 patients were selected, who were admitted with the diagnosis of gallstone and symptomatic gallbladder diseases undergone laparoscopic cholecystectomy in Dhaka Medical College Hospital \& BSMMU, Dhaka, Bangladesh. Patients were selected irrespective of their age, sex, fit for laparoscopic cholecystectomy. Results: This study represents the experiences with 100 patients who are admitted with the clinical and ultrasonographic diagnosis of gallstone and symptomatic gallbladder disease for laparoscopic cholecystectomy. Operation time was from 30-90 minutes with a mean time of 47.4 minutes. Typical clinical presentation was found in most of the cases. 15 (15\%) patients presented with epigastric pain of which $12(12 \%)$ patients were misdiagnosed and were treated for duodenal ulcer for years. $1(1 \%)$ patient was diagnosed incidentally during ultrasonography for gynaecological complaints. All the patients in this study undergone ultrasonography of hepatobiliary system and pancreas. Out of 100 cases 93 (93\%) cases were found to have stone in gallbladder sonologically, whereas $96(96 \%)$ cases were found to have stone in the gallbladder peroperatively. Ultrasonography detected normal appearance gallbladder with stone in 73 (73\%) cases but peroperatively found them in $76(76 \%)$ cases. In $15(15 \%)$ cases sonography revealed fibrosed and contracted gallbladder with stone, whereas $13(13 \%)$ cases were found to have the findings per-operatively. Sonography commented $7(7 \%)$ patients of thick gallbladder wall where per-operatively it was found in $11(11 \%)$ patients. Distended gallbladder with stones was detected sonologically in $6(6 \%)$ cases but peroperatively found them in 7 (7\%) cases. In $1(1 \%)$ case sonography detected fibrosed and contracted gallbladder without stones but per-operatively such was found in $2(2 \%)$ cases. Gallbladder polyp was found in $1(1 \%)$ case both sonologically and peroperatively. No adhesions and stone in common bile duct were detected by sonologically. Conclusion: Considering and comparing data in this series it can be concluded that, sound clinical examination with ultrasonographic evaluation of gallstone and symptomatic gallbladder disease is almost accurate in real time laparoscopic cholecystectomy.

Keywords: Clinical presentation, Laparoscopic cholecystectomy, Detected sonologically, Gallbladder wall.

Copyright @ 2020: This is an open-access article distributed under the terms of the Creative Commons Attribution license which permits unrestricted use, distribution, and reproduction in any medium for non-commercial use (NonCommercial, or CC-BY-NC) provided the original author and source are credited.

\section{INTRODUCTION}

Gallbladder disease is a worldwide common surgical problem. Before the advent of the laparoscopic cholecystectomy, open cholecystectomy was the standard modality of treatment for cholelithiasis and symptomatic gallbladder diseases. Carl Langenbuch performed the first open cholecystectomy in 1882, since then this technique had remained the 'gold standard' for the treatment of symptomatic cholelithiasis and acute cholecystitis for more than 100 years throughout the world [1]. The first laparoscopic cholecystectomy was performed by Erich Muhe, a surgeon from Boblingen performed first laparoscopic cholecystectomy in 1985. Unfortunately his technical presentation to Congress of 
German Surgical Society met with considerable resistance. The surgery was later performed with the help- of video camera in France by Phillipe Mouret in 1987. In 1988, Dubios had started to perform laparoscopic cholecystectomy regularly [2, 3]. Since then, laparoscopic cholecystectomy is the procedure of choice for the majority of patient with gall bladder diseases [4]. In our country, laparoscopic cholecystectomy was first introduced in 1991 at BIRDEM and former IPGMR by a group of surgeons led by Professor Hashimoto of Japan. Since then it has gained its wide acceptance in our country and is practiced in almost all medical college hospital of Bangladesh and many private clinics in Dhaka city as well as other parts of the country [5]. The introduction of laparoscopic cholecystectomy in 1988 was followed by a dramatic shift from open cholecystectomy to the laparoscopic approach. The benefits of laparoscopic surgery include reduced postoperative morbidity and pain, shortened hospitalization, quicker return to a normal lifestyle and lower overall health care expenses [6]. Transabdominal ultrasongraphy is the initial imaging modality of choice in gall bladder disease as it is accurate, readily available, inexpensive and quick to perform [7]. It is very sensitive and specific in detecting biliary stones and dilatation of bile ducts and requires minimal preparation, avoids radiation and side effects of contrast media, is independent of liver function and gastrointestinal upset. So it is a good tool of evaluation and many times match with peroperative findings in gall bladder diseases, however, it is operator dependent and may be suboptimal due to excessive body fat and intraluminal bowel gas[7].Clinical findings of the patient of gall bladder disease are very important but it may give wrong information. A patient with cholelithiasis without history of obstructive jaundice, ultrasonography may detects no stone in CBD but on laparoscope found dilated common bile duct with stone inside. Some of the patients may present with excessive adhesions, empyema gall bladder or stones in common bile duct on laparoscope, which are not clinically and sonologically obvious $[8,9]$. The purpose of the study is to compare the accuracy of the diagnosis of gallstone symptomatic gallbladder diseases by clinical and ultrasonographic findings with peroperative findings of laparoscopic cholecystectomy. Subsequently transduodenal sphincteroplasty also become another important additional operative procedure for biliary tract disease. Dr. Louis L. Smith and S. Austin Jones of America coined the term "Sphincteroplasty" in 1952 [6, 10]. So until recently, open cholecystectomy remains as a standard treatment modality for gallbladder diseases. But recently laparoscopic cholecystectomy (LC) has been introduced in the era of minimal access surgery as the newest treatment modality for management of galladder diseases $[4,10]$ Laparoscopic cholecystectomy was first accomplished in July 1987 by a French Gynaecologist named Philipe Mouret in Lyons. Subsequently, it gained wide acceptance. In Bangladesh, it was first demonstrated in December
1991 on two patients in BIRDEM Hospital and the former IPGM\&R by Dr. Hasimoto from Japan and Dr. Sarder A. Nayeem of Bangladesh. Subsequently in April 1993 Dr. Nayeem started laparoscopic cholecystectomy in Bangladesh in BIRDEM Hospital. Now it is being practiced in many government hospitals and private clinics in our country [5]. In present study, we have tried to compare the effectiveness and accuracy of clinical and ultrasonographic evaluation with real time findings during laparoscopic cholecystectomy.

\section{AIMS AND OBJECTIVES}

The suitability of a case gallstone and symptomatic gallbladder disease for laparoscopic cholecystectomy is very much judge on the basis of a good well descriptive sonological findings. It is highly sensitive as well as specific to detect gall stone but less sensitive in detecting ductal calculus. Sometimes it may give false negative result about gall stone and fibrosed contracted gall bladder. Similarly clinical findings are very important but may be inconclusive.

\section{OBJECTIVES}

- To see the accuracy of clinical diagnosis after ultrasonographic evaluation of gallstone and symptomatic gallbladder disease.

- To compare preoperative ultrasonographic findings with peroperative findings of laparoscopic cholecystectomy to determine percentage of real time accuracy in diagnosis of gallstone and symptomatic gallbladder disease.

- To compare ultrasonographic and peroperative morphological findings of diseased gallbladder.

\section{MATERIALS AND METHODS Study Design}

It is a prospective study.

\section{Study population}

Patients admitted in surgery wards from emergency \& outpatient department with the diagnosis of gallstone and symptomatic gallbladder disease.

\section{Study site}

Dhaka Medical College Hospital \& BSMMU, Dhaka, Bangladesh

\section{Sampling method}

Quantitative sampling technique was used in the present study.

\section{Sample size}

Total 100 patients were selected, who were admitted with the diagnosis of gallstone and symptomatic gallbladder diseases undergone laparoscopic cholecystectomy in Dhaka Medical College Hospital \& BSMMU, Dhaka. 


\section{Sampling technique}

Sample were selected through inclusion and exclusion method rom the patients who were addmitted in surgery department of Dhaka Medical College Hospital \& BSMMU, diagnosed clinically and ultrasonographycally as gallstone and symptomatic gallbladder diseases.

\section{Study tools}

Patients admitted in the hospitals through emergency \& outpatient department, were diagnosed on the basis of clinical history, examination, laboratory data and ultrasonographic findings. In course of management laparoscopic cholecystectomy findings were recorded.

\section{Study period}

Total study period expected to be around 12 months (January, 2008-January, 2009). However, the participants were enrolled over 8 months with the hope that this time period will be enough to enroll required number of cases.

\section{DATA ANALYSIS}

The study was conducted according to the protocol attached herewith. After collection of data according to data sheet, a detailed analysis of the various aspects of clinical findings, ultrasonographic evaluation and per-operative findings during laparoscopic cholecystectomy were made. All data analysis Windows SPSS version 19.0.

\section{RESULTS}

This study represents the experiences with 100 patients who are admitted with the clinical and ultrasonographic diagnosis of gallstone and symptomatic gallbladder disease for laparoscopic cholecystectomy in Dhaka medical college hospital and BSMMU from January'08 to January'09. All the patients underwent standard 4 ports laparoscopic cholecystectomy by experienced surgical teams. Operation time was from 30-90 minutes with a mean time of 47.4 minutes. The normal adult with an intact hepatic circulation and consuming an average diet secrets 250 to $1000 \mathrm{ml}$ of bile per day, average $40 \mathrm{ml}$ per hour from the hepatic cells. There is a diurnal variation, more being secreted in the daytime than at night. Secretion of bile is an active process, which is dependent upon hepatic blood flow and an oxygen supply available to the hepatic cell.

Table-1: Composition of hepatic duct bile $(n=100)$

\begin{tabular}{|l|c|}
\hline Contents & Percentage $\mathbf{( \% )}$ \\
\hline Water & 97.0 \\
\hline Bile salts & 0.70 \\
\hline Bile pigments & 0.20 \\
\hline Cholesterol & 0.06 \\
\hline Inorganic salt & 0.70 \\
\hline Fatty acids & 0.15 \\
\hline Lecithin & 0.10 \\
\hline Fat & 0.10 \\
\hline
\end{tabular}

Table-2: Comparison between hepatic duct bile and gallbladder bile $(n=100)$

\begin{tabular}{|l|c|c|}
\hline Contents & Hepatic duct bile & Gallbladder bile \\
\hline Percentage of solid & $2-4 \%$ & $10-12 \%$ \\
\hline Bile salts (mmol/L) & $10-12$ & $50-200$ \\
\cline { 1 - 1 } $\mathrm{pH}$ & $7.8-8.6$ & $7.0-7.4$ \\
\hline
\end{tabular}

The main constituents of bile include electrolytes, bile, proteins, cholesterol, fats and bile pigments. Sodium, potassium, calcium and chloride have approximately the same concentration in bile as in plasma. There is a direct relation between the rate of secretion and the electrolytes concentration. As the former increases, there is an increase in bicarbonate and
$\mathrm{pH}$ and a slight in chloride. The $\mathrm{pH}$ of liver bile which is usually range between 7.8 and 8.6 tending to the alkaline side varies with the diet. An increase in protein ingestion shifting the $\mathrm{pH}$ to the acid side. Liver bile becomes concentrated 5-10 times in gallbladder by absorption of water, sodium, chloride and bicarbonate [Table-1 \&2].

Table-3: Distribution of patients by sex $(n=100)$

\begin{tabular}{|l|c|c|}
\hline Sex & Number of patients & Percentage (\%) \\
\hline Female & 71 & 71.0 \\
\hline Male & 29 & 29.0 \\
\hline
\end{tabular}

Table-4: Distribution of patients by age $(n=100)$

\begin{tabular}{|l|c|c|}
\hline Age in years & Number of patients & Percentage (\%) \\
\hline$<20$ & $01(\mathrm{M}-0, \mathrm{~F}-1)$ & 01 \\
\hline $21-30$ & $17(\mathrm{M}-3, \mathrm{~F}-14)$ & 17 \\
\hline $31-40$ & $38(\mathrm{M}-12, \mathrm{~F}-26)$ & 38 \\
\hline $41-50$ & $24(\mathrm{M}-7, \mathrm{~F}-17)$ & 24 \\
\hline $51-60$ & $14(\mathrm{M}-4, \mathrm{~F}-10)$ & 14 \\
\hline $61-70$ & $04(\mathrm{M}-2, \mathrm{~F}-2)$ & 04 \\
\hline$>70$ & $02(\mathrm{M}-1, \mathrm{~F}-1)$ & 02 \\
\hline
\end{tabular}


In this series, 100 cases admitted in Dhaka medical college hospital and BSMMU with gallstones and symptomatic gallbladder disease during the period of January' 2008 to January' 2009. Both female and male cases were studied randomly of which 71 were female and 29 male [Table 3]. A fat, fertile, flatulent, female of forty is the classical sufferer from symptomatic gallstone disease. In this series 1 patient was 19 years of age, 17 patients were between 21-30 years of age, 38 patients were 31-40 years of age, 24 patients were 41-50 years of age and 14 patients were in between 51-60 years of age, four patients was 61-70 years of age and 2 patients were above 70 years. Highest incidence was in the 3 rd decade $(38 \%)$ [Table 4].

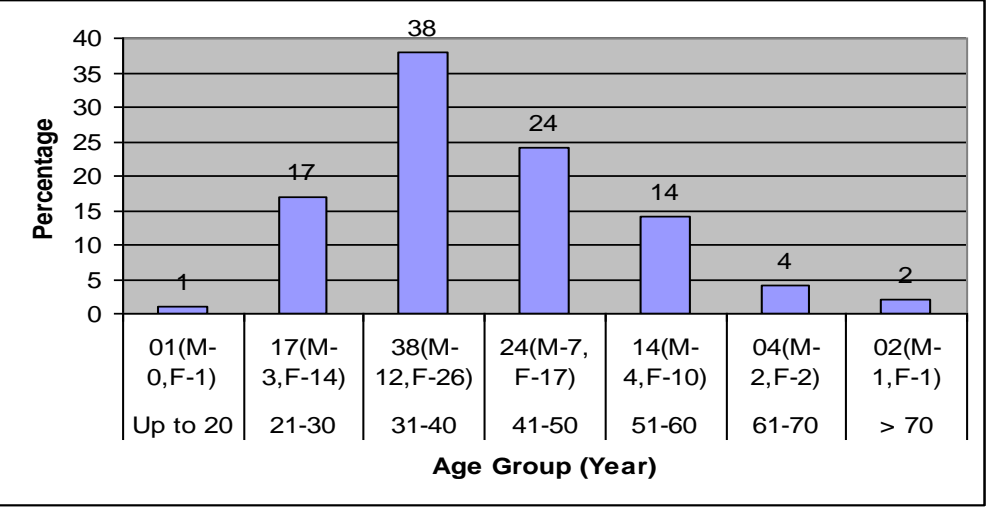

Fig-1: Bar diagram showing distribution of patients by age $(n=100)$

Table-5: Clinical presentation of patients $(n=100)$

\begin{tabular}{|l|c|c|}
\hline Symptoms/ signs & Number of patients & Percentage (\%) \\
\hline Pain in the right hypochondrium & 95 & 95 \\
\hline Flatulence dyspepsia & 68 & 68 \\
\hline Nausea/Vomiting & 27 & 27 \\
\hline Fatty food intolerance & 57 & 57 \\
\hline Radiation of pain & 26 & 26 \\
\hline Pain in the epigastrium & 15 & 15 \\
\hline Past history of acute attack & 13 & 13 \\
\hline History of jaundice & 01 & 01 \\
\hline Murphy's sign positive & 11 & 11 \\
\hline Palpable gallbladder & 02 & 02 \\
\hline Fever & 03 & 03 \\
\hline Palpable liver & 00 & 00 \\
\hline
\end{tabular}

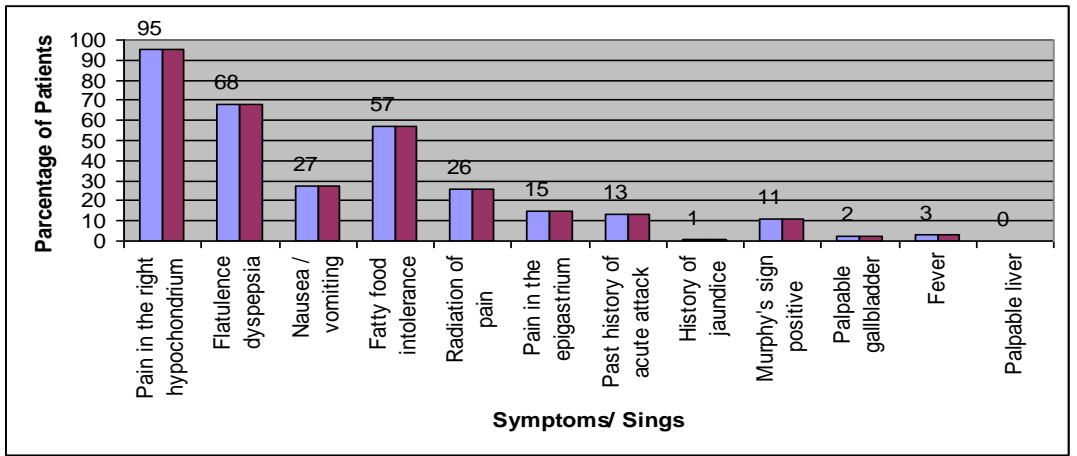

Fig-2: Bar diagram showing clinical presentation of patients $(n=100)$

Table-6: Associated medical diseases $(n=100)$

\begin{tabular}{|l|c|c|}
\hline Diseases & Number of patient & Percentage (\%) \\
\hline Diabetes mellitus & 16 & 16 \\
Hypertension & 13 & 13 \\
COPD & 02 & 02 \\
IHD & 03 & 03 \\
\hline
\end{tabular}

COPD, chronic obstructive airway disease; IHD, ischemic heart disease 
Murphy's sign was positive in (11\%) patient. $15 \%$ cases presented with pain in the epigastrium which was diagnosed primarily as chronic duodenal ulcer and was treated accordingly. Many patients (57\%) had history of fatty food intolerance. $1 \%$ patients had past history of jaundice that was not consistent with obstructive jaundice [Table 5]. In this study, 16 patients had diabetes mellitus, 13 patients had hypertension among which 5 patients had also diabetes and 3 patients had ischaemic heart disease among which one patient had also diabetes. Only 2 patients had chronic obstructive pulmonary disease with no diabetes and hypertension. Patients with IHD were further evaluated by echocardiography [Table 6].

Table-7: Past history of abdominal surgery $(n=100)$

\begin{tabular}{|l|c|c|}
\hline Location of surgery & Number of patients & Percentage (\%) \\
\hline Upper abdomen & 00 & 00 \\
\hline Lower abdomen & 13 & 13 \\
\hline
\end{tabular}

CBD, common bile duct

In this series no patients had previous history of upper abdominal surgery though past history of such operation is a relative contraindication of such surgery but technical skill which has now developed in surgical community, eliminated this contraindication. Thirteen of them had lower abdominal surgery [Table 7], all were caesarean section and abdominal hysterectomy and no problem was encountered in doing laparoscopic cholecystectomy on those patients. All the patients in the present series underwent ultrasonography of the hepatobiliary system and pancreas.

Table-8: Ultrasonographic findings of patients $(n=100)$

\begin{tabular}{|l|c|c|}
\hline Ultrasonographic findings & Number of patients & Percentage (\%) \\
\hline Normal appearance gallbladder-with stones & 73 & 73 \\
\hline $\begin{array}{l}\text { Fibrosed and contracted gallbladder- } \\
\text { with stones }\end{array}$ & 15 & 15 \\
\hline Distended gallbladder with stones & 06 & 06 \\
\hline $\begin{array}{l}\text { Fibrosed and contracted gallbladder- } \\
\text { without stones }\end{array}$ & 01 & 01 \\
\hline Thick gallbladder wall & 07 & 07 \\
\hline Dense adhesions & 02 & 02 \\
\hline Gallbladder polyp & 01 & 01 \\
\hline Dilated CBD or CBD stone & 00 & 00 \\
\hline
\end{tabular}

In this study $73(73 \%)$ cases were found to have normal appearance gallbladder with stones sonologically, but per-operatively such found in 76 $(76 \%)$ cases. In $15(15 \%)$ cases revealed fibrosed and contracted gallbladder with stones, whereas $13(13 \%)$ cases were found to have the findings peroperatively indicating that ultrasonography had given two false positive results regarding fibrosed and contracted gallbladder which were really normal appearance gallbladder.

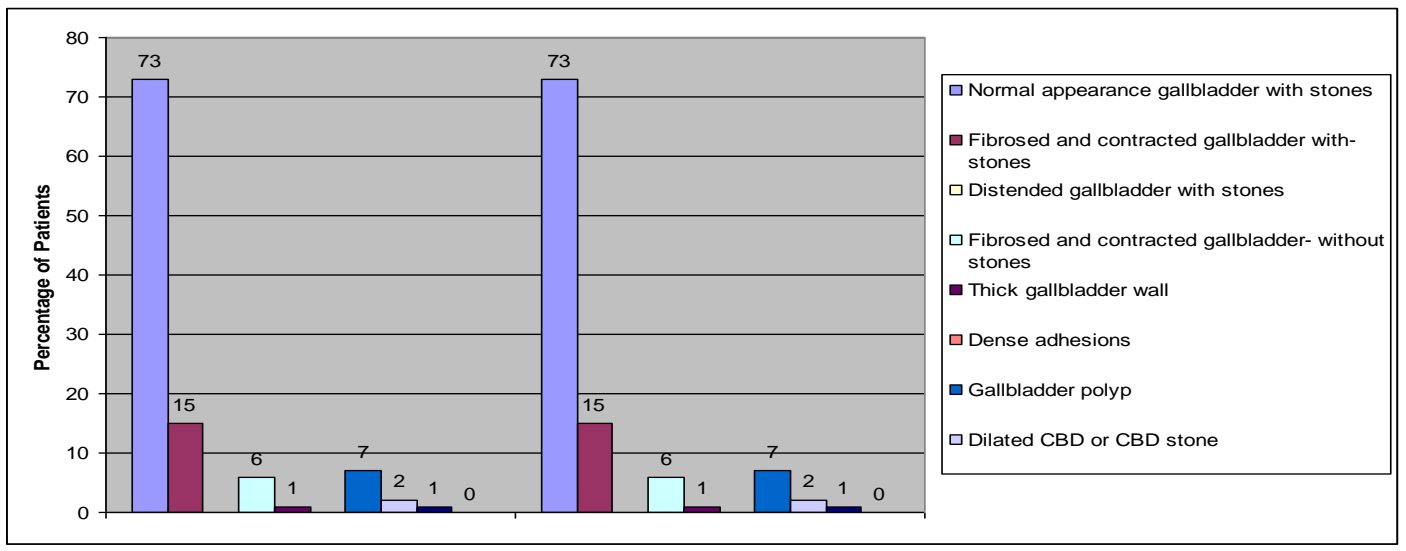

Fig-3: Bar diagram showing ultrasonographic findings of patients $(n=100)$ 
Table-9: Peroperative laparoscopic findings of patients $(\mathbf{n}=100)$

\begin{tabular}{|l|c|c|}
\hline $\begin{array}{l}\text { Ultrasonographic } \\
\text { findings }\end{array}$ & $\begin{array}{c}\text { Number of } \\
\text { patients }\end{array}$ & Percentage (\%) \\
\hline Normal appearance gallbladder- with stones & 76 & 76 \\
\hline Fibrosed and contracted gallbladder- with stones & 13 & 13 \\
\hline Distended gallbladder with stones & 07 & 07 \\
\hline Fibrosed and contracted gallbladder- without stones & 02 & 02 \\
\hline Thick gallbladder wall & 11 & 11 \\
\hline Dense adhesions & 02 & 02 \\
\hline Gallbladder polyp & 01 & 01 \\
\hline Short cystic duct & 04 & 04 \\
\hline Stone in dilated bile duct & 01 & 01 \\
\hline Intrahepatic gallbladder & 01 & 01 \\
\hline
\end{tabular}

Table-10: Comparison of ultrasonography and peroperative findings during laparoscopic cholecystectomy

\begin{tabular}{|l|c|c|c|c|}
\hline Findings & \multicolumn{2}{|c|}{ Ultrasonographic } & \multicolumn{2}{c|}{ Laparoscopic } \\
\hline & Number & Percentage & Number & Percentage \\
\hline Gallbladder containing stones & 93 & 93 & 96 & 96 \\
\hline Normalappearance gallbladder with stones & 73 & 73 & 76 & 76 \\
\hline $\begin{array}{l}\text { Fibrosed and contracted gall- } \\
\text { bladder with stones }\end{array}$ & 15 & 15 & 13 & 13 \\
\hline Distended gallbladder with stones & 06 & 06 & 07 & 07 \\
\hline $\begin{array}{l}\text { Fibrosed and contracted gall- } \\
\text { bladder without stones }\end{array}$ & 01 & 01 & 02 & 02 \\
\hline Gallbladder polyp & 01 & 01 & 01 & 01 \\
\hline Dense adhesions & 00 & 00 & 03 & 03 \\
\hline Thick gallbladder wall & 07 & 07 & 11 & 11 \\
\hline Short cystic duct & 00 & 00 & 04 & 04 \\
\hline Stone in dilated bile duct & 00 & 00 & 01 & 01 \\
\hline Intrahepatic gallbladder & 00 & 00 & 01 & 01 \\
\hline
\end{tabular}

In this study out of 100 cases $93(93 \%)$ cases were found to have stones in gallbladder on ultrasonography, whereas $96(96 \%)$ cases were found to have stones in gallbladder per-operatively indicating that ultrsonography had given three false negative results, correlates with the findings. In this study 73 $(73 \%)$ cases were found to have normal appearance gallbladder with stones sonologically, but peroperatively such found in $76(76 \%)$ cases. In 15 (15\%) cases revealed fibrosed and contracted gallbladder with stones, whereas $13(13 \%)$ cases were found to have the findings peroperatively indicating that ultrasonography had given two false positive results regarding fibrosed and contracted gallbladder which were really normal appearance gallbladder, correlates with the findings. Sonography commented 7 patients of thick gallbladder wall where per-operatively it was found in 11 patients. In $6(6 \%)$ cases were found to have distended gallbladder with stones sonologically but peroperatively found in $7(7 \%)$ cases indicating ultrasonography had given one false negative results about distended gallbladder [Table 9-10].

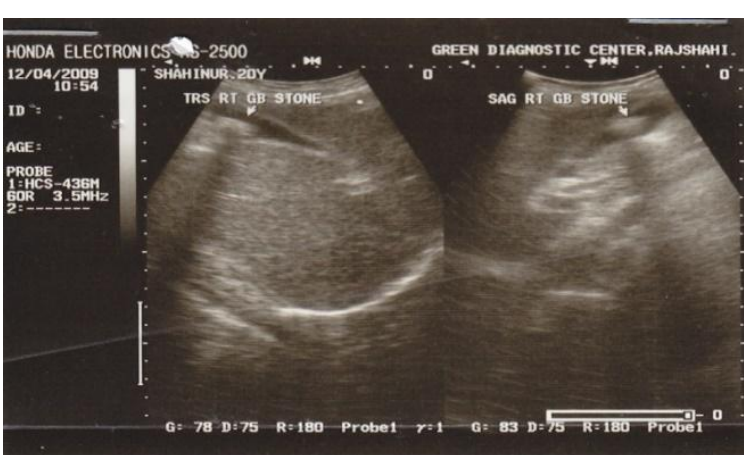

Fig-4: Ultrasonography showing Cholelithiasis

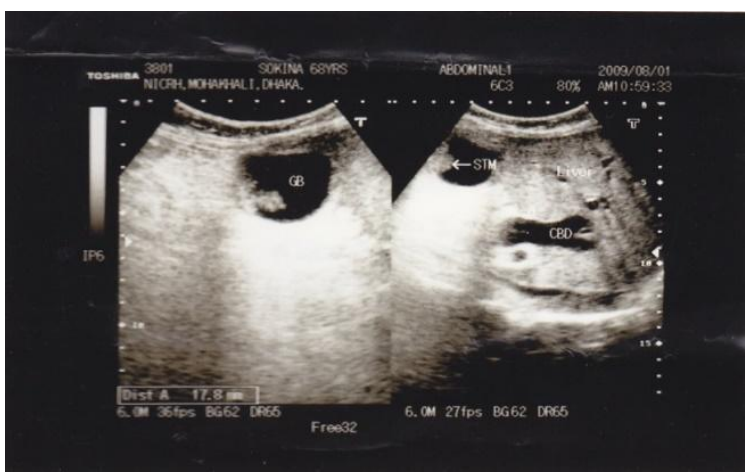

Fig-5: Ultrasonography showing soft tissue mass in G.B with dilated CBD 
Fasting for six should ensure distension of gallbladder for visualization of the lumen. Scanning in two positions, supine and left lateral positions, ensures optimal visualization with a 3.5 or $5 \mathrm{MHz}$ probe. Normal gallbladder contains anechoic bile and has a mural thickness of $3 \mathrm{~mm}$ or less. High frequency scanning is able to define the layers of mucosa, muscularis and serosa. Contraction is demonstrable following fatty meal. The spiral valve of Heister appears echogenic with acoustic shadowing. The accuracy of ultrasound in detecting gallstone is over $98 \%$; false negatives are usually due to observer error or technical limitations such as patient's obesity. Gallstones are characteristically echogenic casting posterior acoustic shadow. Consequent to their crystalline matrix often on the dependent portion of the gallbladder. They may change their position as the patient's position changes but this is an inconsistent feature [Figure $4 \& 5$ ].

Table-11: Operative time (in minutes) in laparoscopic cholecystectomy $(n=100)$

\begin{tabular}{|l|l|l|l|}
\hline Number of cases & Range (min) & Mean (min) & Median (min) \\
\hline 100 & $30-90$ & 47.4 & 50 \\
\hline
\end{tabular}
[Table-11).

Mean time required for laparoscopic cholecystectomy on this series was $47.4 \mathrm{~min}$. which range from 30-90 min

Table-12: Incidence of calculous versus acalculous cholecystitis $(\mathbf{n}=100)$

\begin{tabular}{|l|c|c|}
\hline Nature of cholecystitis & Number of patient & Percentage (\%) \\
\hline Calculous & 95 & 95 \\
Acalculous & 5 & 5 \\
\hline
\end{tabular}

In a study high diagnostic effectiveness of ultrasound examination in acute cholecystitis (95.5\%) is demonstrated [Table 12].

Table-13: Postoperative problems \&amp; complications (n=100)

\begin{tabular}{|l|c|c|}
\hline Problems and complications & No. of patients & Percentage \\
\hline Vomiting / right hypochondriac pain & 05 & 05 \\
\hline Port site infection (Obese patients) & 02 & 02 \\
\hline Decreased pulmonary function and mild chest infection & 02 & 02 \\
\hline
\end{tabular}

Table-14: Ambulatory time after operation $(n=100)$

\begin{tabular}{|c|c|}
\hline Range (hours) & Mean (hours) \\
\hline $10-24$ & 12 \\
\hline
\end{tabular}

It is observed from the present series that improved result was obtained by laparoscopic chollecystectomy in respect of much reduced postoperative complications (table 13), early ambulation; most of the patients were ambulatory after 12 hours [Table 14], shorter hospital stay (1-5 days) mean 2.4 days, patients returned to their normal activity very fast (range 5- 12 days, mean 7 days), and almost invisible scar. Only 9 patients had some degree of postoperative problems or complications in the form of vomiting and right hypochondriac pain (5 patients), port site infection ( 2 patients), mild chest infection (2 patients).Vomiting was controlled by antiemetics, 2 patients had umbilical port infection which were healed by regular dressing and antibiotics.

\section{DISCUSSION}

The approach to the patient with cholelithiasis and symptomatic gallbladder disease has undergone a rapid evolution since the introduction of laparoscopic cholecystectomy. Initially there were plethoras of contraindications, which are becoming obsolete as the evolving clinical experience of pioneering surgeons.
The usual candidate is the patient with uncomplicated symptomatic cholelithiasis. During the evolution of laparoscopic cholecystectomy, the patient that have acute cholecystitis, obesity, prior surgery and common bile duct stones have undergone laparoscopic cholecystectomy with successful result. Laparoscopic cholecystectomy has become preferred treatment for cholecystitis because of its shorter hospital stay, ease of recovery, shorter operative time, cost effective, minimum post-operative pain and better cosmesis having almost every case. Thereafter majority of cases of cholecystis can be successfully operated laparoscopically, about $2-8 \%$ cases may need conversion into open cholecystectomy for successful completion of cholecystectomy or to overcome varying problems that a surgeon may encounter with during laparoscopic procedure [11]. Ulrasonography has become the most important method of examination of gallbladder. In chronic calculus cholecystitis and in choledocholithiasis the ultrasound examination appeared to be accurate in $97 \%$ and $84.2 \%$ cases respectively [12]. With increasing technical sophistication and expertise, the diagnostic yields and accuracy of ultrasonography in the detection of gallbladder disease have recognized as the superior method of investigation. So, ultrasonography is a useful screening test for patient undergoing laparoscopic cholecystectomy and it can help to predict technical 
difficulties. On the other hand, a relevant number of cases still exist wherein the concordance between the preoperative ultrasonography and surgical findings are unsatisfactory [13]. In the present study our aims were to comparison between preoperative clinical and sonological evaluation and per-operative findings during laparoscopic cholecystectomy. In this series, 100 cases admitted in Dhaka medical college hospital and BSMMU with gallstones and symptomatic gallbladder disease during the period of January' 2008 to January' 2009. Both female and male cases were studied randomly of which 71 were female and 29 male. A fat, fertile, flatulent, female of forty is the classical sufferer from symptomatic gallstone disease. In this series 1 patient was 19 years of age, 17 patients were between 21-30 years of age, 38 patients were 31-40 years of age, 24 patients were 41-50 years of age and 14 patients were in between 51-60 years of age, four patients was 61-70 years of age and 2 patients were above 70 years. Highest incidence was in the 3 rd decade $(38 \%)$. The usual presentation was pain in the right hypochondriac region $(95 \%)$ which correlates with the findings of Huber [14] (88\%), flatulent dyspepsia (68\%), characteristic radiation of pain to the back or right shoulder was experienced in (26\%) cases. Murphy's sign was positive in $(11 \%)$ patient. $15 \%$ cases presented with pain in the epigastrium which was diagnosed primarily as chronic duodenal ulcer and was treated accordingly. Many patients $(57 \%)$ had history of fatty food intolerance. $1 \%$ patients had past history of jaundice that was not consistent with obstructive jaundice. In this study, 16 patients had diabetes mellitus, 13 patients had hypertension among which 5 patients had also diabetes and 3 patients had ischaemic heart disease among which one patient had also diabetes. Only 2 patients had chronic obstructive pulmonary disease with no diabetes and hypertension. Patients with IHD were further evaluated by echocardiography. In this series no patients had previous history of upper abdominal surgery though past history of such operation is a relative contraindication of such surgery but technical skill which has now developed in surgical community, eliminated this contraindication. Thirteen of them had lower abdominal surgery, all were caesarean section and abdominal hysterectomy and no problem was encountered in doing laparoscopic cholecystectomy on those patients. All the patients in the present series underwent ultrasonography of the hepatobiliary system and pancreas. In this study out of 100 cases 93 (93\%) cases were found to have stones in gallbladder on ultrasonography, whereas $96(96 \%)$ cases were found to have stones in gallbladder per-operatively indicating that ultrsonography had given three false negative results, correlates with the findings of Tan [15]. In this study $73(73 \%)$ cases were found to have normal appearance gallbladder with stones sonologically, but per-operatively such found in $76(76 \%)$ cases. In 15 $(15 \%)$ cases revealed fibrosed and contracted gallbladder with stones, whereas $13(13 \%)$ cases were found to have the findings peroperatively indicating that ultrasonography had given two false positive results regarding fibrosed and contracted gallbladder which were really normal appearance gallbladder, correlates with the findings of Schmer[16]. Sonography commented 7 patients of thick gallbladder wall where per-operatively it was found in 11 patients. In $6(6 \%)$ cases were found to have distended gallbladder with stones sonologically but per-operatively found in 7 (7\%) cases indicating ultrasonography had given one false negative results about distended gallbladder. One (1\%) case were found to have fibrosed and contracted gallbladder without stones sonologically, whereas 2 (2\%) cases were found to have that findings peroperatively indicating that ultrasonography had given one false negative results about stones in the fibrosed and contracted gallbladder[17]. In this study gallbladder polyp was found in $1 \%$ case both in ultrasonography and per-operatively. No dense adhesions were found in sonologically but peroperatively dense difficult adhesions were found in 3 (3\%) cases. One case of intrahepatic gallbladder, 4 cases of short cystic duct which were found peroperatively but not found sonologically. In one case stone found in dilated common bile duct per-operatively but not sonologically. Also this patient clinically showed no features of chodocholithiasis correlates with the findings of Gelfand[18]. Ultrasonography is the best diagnostic tool for detecting gallstones. Sonological results are accurate and false negative reports are rare if sonographers and radiologists are experienced. In the study by Chintapalli KN revealed that despite of improvement of sonological technology, detection of gallstones remains difficult in some cases (false negative rate was $1.2 \%$ ). In a study by Sazhn-VP[12], high diagnostic effectiveness of ultrasound examination in acute cholecystitis (95.5\%) is demonstrated. In chronic calculus cholecystitis and in choledocholithiasis the ultrasound examination appeared to be accurate in $97.0 \%$ and $84.2 \%$ of cases respectively. Ultrasonography of hepatobiliary system can be recommended as useful investigation for selecting the cases for laparoscopic cholecystectomy because good and expert ultrasound examination of gallbladder reliably predicts the degree of difficulty of procedure. In this respect the most important finding is a maximum gallbladder wall thickness more than $4 \mathrm{~mm}$ [19]. This finding is indicative of a contracted gallbladder, which is difficult to grasp (in the present series only 5\% false negative by sonography). A large stone impacted in Hartmann's pouch creates problems in dissection of cystic duct and artery [20]. Good sonologist gives the information about gallbladder size, site, and number of stones, gallbladder wall thickness and condition of common bile duct. In the present study except few cases most of the operative findings were correlated with preoperative ultrasonographic findings, correlates with findings of Gelfand[17]. All patients were operated under general anesthesia adopting the more popular American approach with a standard 4-port technique. 
Mean time required for laparoscopic cholecystectomy on this series was $47.4 \mathrm{~min}$. which range from 30-90 min. Longer time was required in the patient having dense adhesions. The times are nearer to the report by Bake-AA[21] (43 minutes) but lower than Watson DI[22] (90 minutes). This might be due to patient selection and evolution of surgical technique and experience with time. It is observed from the present series that improved result was obtained by laparoscopic chollecystectomy in respect of much reduced post-operative complications, early ambulation; most of the patients were ambulatory after 12 hours, shorter hospital stay (1-5 days) mean 2.4 days, patients returned to their normal activity very fast (range 5- 12 days, mean 7 days), and almost invisible scar. Only 9 patients had some degree of postoperative problems or complications in the form of vomiting and right hypochondriac pain (5 patients), port site infection (2 patients), mild chest infection (2 patients).Vomiting was controlled by antiemetics, 2 patients had umbilical port infection which were healed by regular dressing and antibiotics. Mild chest infection developed in only 2 patients who were recovered by chest physiotherapy and other measures. There was no other major postoperative complication. These are comparable with other studies [23-26]. To determine uncomplicated gallstone disease utrasonography has become the dominant method of investigation. This has occurred because ultrasonography is a convenient and safe initial investigation. It is also sensitive and specific accurate method for diagnosing gallstone disease.

\section{CONCLUSION}

Considering and comparing data in this series it can be concluded that, sound clinical examination with ultrasonographic evaluation of gallstone and symptomatic gallbladder disease is almost accurate in real time laparoscopic cholecystectomy. The outcome of clinical evaluation and ultrasonographic findings are influenced largely by knowledge, training, experience, skill and sound judgment. So, proper clinical examination is a must with ultrasonography can be recommended as the most useful investigation for selecting the case for laparoscopic cholecystectomy.

\section{REFFERENCE}

1. Martin IG. Laparoscopic Cholecystectomy as a routine procedure for gallstones, results of "all comers" policy. BJS. 1992; 79: 807-10.

2. Acosta AS, Fares RG. Arguller VG. Laparoscopic Cholecystectomy: A safe treatment option or a passing fancy. Proceedings MMC, 1992; 6: 9-14.

3. John K, Sutton D. The Test Book of Radiology and Imaging, Seventh ed. Churchill Livingstone, London. 2002; 1:714-17.

4. Glenn F, William R. Historical events in biliary surgery. Arch surg. 1966; 93: 848-52.

5. Anis M. Review of 100 cases of laparoscopic Cholecystectomy (Dissertation), Dhaka.
Bangladesh College of Physicians \& Surgeons, 2004.

6. Nath R.K. Post-Operative Complication of biliary surgey: A study of 100 cases (Dissertation) Dhaka. Bangladesh College of Physicians and Surgeons; 1990.

7. Saleh JW. Laparoscopy. Philadelphia: WB Saunders Co; 1998; 7-8.

8. Mamunur R. Peroperative and early postoperative complication of laparoscopic Cholecystectomy (Dissertation) Dhaka. A prospective study of 100 cases, BIRDEM Hospital; 2000.

9. Philipi CJ, Fitzgibbons RJ, Salerno GM. Historical Review:: Diagnostic laparoscopy to laparoscopic Cholecystectomy and Beyond. In: Zucker KA, ed. surgical laparoscopy. St. Lou, MO: Quality Medical publishing, Inc. 1991;3-21.

10. Hannan ABM. Review of common bile duct exploration: A study of 30 cases. [DissertationSurgery]. Dhaka: BCPS; 1989.

11. Z'graggen-K; Wehrli-H, Complictions of laparoscopic cholecystectomy in Switzerland. A prospective 3 years study of 10, 174 patients, Surg Endosc; 1998; 12(11): 1303-10.

12. Sazhim-VP, Zhabolenko-VP. Compartive aspects of the diagnosis of diseases of organs of the hepatopancreatico-duodenal zone, Khirurgiia-Mosh. 1996; 97(3): 45-8.

13. Santambrogio-R, Montorsi-M. Technical difficulties and complications during laparoscopic cholecystectomy: Predictive use of Preparative ultrasonography. World- J- Surg. 1996; 20(8): 97882.

14. Huber DF, Martin EW, Cholecystectomy in elderly patients, Am J Surg. 1983 Dec; 146 (4): 719-722.

15. Tan JSC. Comparison of accuracy of ultrasonography and oral cholecystography in diagnosis of cholethiasis.Singapore Med J. 1998; 29:? 485-88.

16. Schermer BD Oria-HE. Pitfalls in the diagnosis of gallbladder disease in clinically severe obesity. Obes-surg. 1998 Aug; 8(4): 444-5.

17. Schermer BD. Laparoscopic cholecystectomy in obse patient. Am Surg. 1992; 216:146-52.

18. Gelfand DW. Oral cholecystography vs gallbladder ultrasonography. Am JRadiol. 1998; 151-2.

19. Jansen- S, Jorgensen- J, Preoperative ultrasound to predict conversion in laparoscopic cholecystectomy, surg- Laparosc- Endosc. 1997 Apr; 7(2): 121-3.

20. Cuschieri SA, Steele RJC, Moossa AR, editors. In: Essential Surgical Practice. $4^{\text {th }}$ Ed. Arnold; 2. 2002: 375-44938.

21. Bake-AA, Khalil-ME. Acute cholecystitis is an indication for laparoscopic cholecystectomy: a prospective study. J-Soc-Laparoendosc-surg. 1997 Apr-Jun; 1(2): 119-23.

22. Watson D.I. Mathew G. Impact of Laparoscopic cholecystectomy in a major teaching hospital: 
Clinical and hospital outcomes, Med J. Aust. 1995 Nov; 163(20): 527-30.

23. Tzovaras G,Zacharoulis D,Liakou P, Theodoropoulos T, Paroutoglou G, Hatzitheofilou C. Timing of laparoscopic cholecystectomy for acute cholecystitis: A prospective non randomized study. World Journal of gastroenterology. 2006; 12(34): 5528-553

24. Madan AK, Aliabadi-Wahle S, Donnatesi, Flint LM, Steinberg. How early is early laparoscopic treatment of acute cholecystitis?The American Journal of surgery.2002;183: 232-236

25. Lai PBS, Kwong KH, Leung KL, Kwok SPY, Chan ACW, Chung SCS. Randomized trial of early versus delayed laparoscopic cholecystectomy for acute cholecystitis. British Journal of Surgery. 1998; 85: 764-767

26. Chowdhury ATMM. Selection criteria for laparoscopic cholecystectomy (Dissertation), Dhaka. Bangladesh College of Physicians \& Surgeons, 2001. 